\title{
Exotic weeds and fluctuating microclimate can constrain native plant regeneration in urban forest restoration
}

\author{
K. J. Wallace, ${ }^{1}$ Daniel C. Laughlin, and Bruce D. Clarkson \\ Environmental Research Institute, University of Waikato, Private Bag 3105, Hamilton, 3240 New Zealand
}

\begin{abstract}
Restoring forest structure and composition is an important component of urban land management, but we lack clear understanding of the mechanisms driving restoration success. Here we studied two indicators of restoration success in temperate rainforests: native tree regeneration and epiphyte colonization. We hypothesized that ecosystem properties such as forest canopy openness, abundance of exotic herbaceous weeds, and the microclimate directly affect the density and diversity of native tree seedlings and epiphytes. Relationships between environmental conditions and the plant community were investigated in 27 restored urban forests spanning 3-70 years in age and in unrestored and remnant urban forests. We used structural equation modelling to determine the direct and indirect drivers of native tree regeneration and epiphyte colonization in the restored forests. Compared to remnant forest, unrestored forest had fewer native canopy tree species, significantly more light reaching the forest floor annually, and higher exotic weed cover. Additionally, epiphyte density was lower and native tree regeneration density was marginally lower in the unrestored forests. In restored forests, light availability was reduced to levels found in remnant forests within 20 years of restoration planting, followed shortly thereafter by declines in herbaceous exotic weeds and reduced fluctuation of relative humidity and soil temperatures. Contrary to expectations, canopy openness was only an indirect driver of tree regeneration and epiphyte colonization, but it directly regulated weed cover and microclimatic fluctuations, both of which directly drove the density and richness of regeneration and epiphyte colonization. Epiphyte density and diversity were also positively related to forest basal area, as large trees provide physical habitat for colonization. These results imply that ecosystem properties change predictably after initial restoration plantings, and that reaching critical thresholds in some ecosystem properties makes conditions suitable for the regeneration of late successional species, which is vital for restoration success and long-term ecosystem sustainability. Abiotic and biotic conditions that promote tree regeneration and epiphyte colonization will likely be present in forests with a basal area $\geq 27 \mathrm{~m}^{2} / \mathrm{ha}$. We recommend that urban forest restoration plantings be designed to promote rapid canopy closure to reduce light availability, suppress herbaceous weeds, and stabilize the microclimate.
\end{abstract}

Key words: epiphytes; indicators; introduced species; microclimate; nonnative species; restoration targets; structural equation modeling; temperate rainforest; tree regeneration; urban ecology.

\section{INTRODUCTION}

Forest ecosystems undergo complex successional dynamics (Oliver and Larson 1990), and management actions must mimic these natural dynamics to be successful at restoring degraded forests (Walker et al. 2007, Reid et al. 2016). However, our understanding of the dynamics that occur in restored forests over decadal time scales is limited by a lack of long-term monitoring and the fact that most forest restoration projects have only started within the past few decades (Ruiz-Jaen and Aide 2005, Oldfield et al. 2015, Shoo et al. 2015, Johnson and Handel 2016, Miller et al. 2016). Improving our understanding of the mechanisms that determine the success of long-term forest restoration is a high research priority (Bullock et al. 2011, Suding 2011).

Manuscript received 4 September 2016; revised 26 January 2017; accepted 30 January 2017. Corresponding Editor: Jill S. Baron.

1E-mail: kjc39@students.waikato.ac.nz
Two indicators of successful restoration of temperate rainforests are regeneration of long-lived, shade-tolerant trees (Suganuma and Durigan 2015, Johnson and Handel 2016) and colonization by epiphytes (Oishi and Doei 2015, Reid et al. 2016). Spontaneous dispersal and recruitment of these indigenous, late successional plants into a forest undergoing restoration is an indication that conditions have become suitable for natural forest dynamics to occur without additional management actions (Robinson and Handel 1993, Boudreault et al. 2000, Shoo et al. 2015, Bertacchi et al. 2016). However, the factors that influence regeneration and colonization and the time it takes for conditions to become suitable are unclear in urban forests, which are often fragmented, invaded by aggressive exotic plants, and are constrained by limited seed dispersal and germination (Lehvävirta and Rita 2002, McCauley et al. 2012, Overdyck and Clarkson 2012, Overdyck et al. 2013). Identifying the environmental conditions that promote successful regeneration of native trees and epiphyte colonization in 
forests will clarify processes driving succession (Brown 1993) and will also directly inform restoration practice (Walker et al. 2007, Bertacchi et al. 2016).

Urban ecosystems differ from rural ecosystems (Dobbs et al. 2011, Groffman et al. 2016) and therefore present unique restoration challenges. However, the benefits of ecologically intact urban forest are worth the effort of restoration (Pickett et al. 2011). Research over the past few decades suggests that, aside from providing wildlife habitat (Burghardt et al. 2009, Threlfall et al. 2016), urban forests provide economically valuable ecosystem services such as flooding and climate mitigation (Dobbs et al. 2011, Pickett et al. 2011) and pollutant filtering (Pickett et al. 2011). Additionally, urban forests provide a space in which humans reconnect with nature and enjoy individual health and societal benefits (Groffman et al. 2016). Therefore, urban forest is now prioritized in city planning (Groffman et al. 2016, Threlfall et al. 2016) and practitioners need information about the best practices for successful long-term forest restoration (Dobbs et al. 2011).

Theories of forest dynamics and succession provide the context for understanding how to restore ecosystems that feature plant species that will only establish in mature vegetation, such as shade-tolerant trees (Palmer et al. 1997, Zedler and Callaway 1999, Smale et al. 2001, Laughlin et al. 2008) and vascular epiphytes (Shono et al. 2006, Reid et al. 2016). Urban forest restoration is typically initiated by removing undesirable plants and planting early successional native tree species (Johnson and Handel 2016) that will develop into a structurally complex, diverse native forest. Subsequent responses of vegetation structure, composition, and function are only sometimes monitored (Ehrenfeld and Toth 1997, Wortley et al. 2013), and while these metrics are important for assessing if a restoration target has been achieved, they do not necessarily identify the mechanisms propelling forest succession toward that target.

Abiotic and biotic ecosystem properties constrain restoration success (Suding and Hobbs 2009), and may respond to restoration actions in different ways during ecosystem recovery (Hobbs and Norton 1996, Hobbs and Harris 2001, Suding et al. 2004). Some ecosystem properties reach restoration targets rapidly, whereas others demonstrate linear, lagged, or threshold responses (Fig. 1). Ecosystem properties may also fail to reach targets altogether by falling short of targets or later reverting to an unrestored state (Fig. 1).

Some ecosystem properties reach thresholds during ecological succession that trigger shifts in other ecosystem properties (Temperton et al. 2004). For example, abiotic properties such as microclimate and light availability are key drivers of regeneration in the forest understory (Fig. 2; Tilman 1985, Brown 1993, Palmer et al. 1997, Shono et al. 2006, Sporn et al. 2010, Neufeld and Young 2014). Recognizing these relationships and how they change through time can be crucial for improving management decisions and facilitating desired plant community assembly (Palmer et al. 1997, Temperton et al. 2004, Suding and Gross 2006, Laughlin 2014).

Biotic thresholds include the loss of native species and the invasion of exotic species, which can also affect the abiotic conditions of a site (Hobbs et al. 2009). Sometimes succession is arrested in an alternative stable state (Hobbs and Norton 1996) or redirected because the microclimate

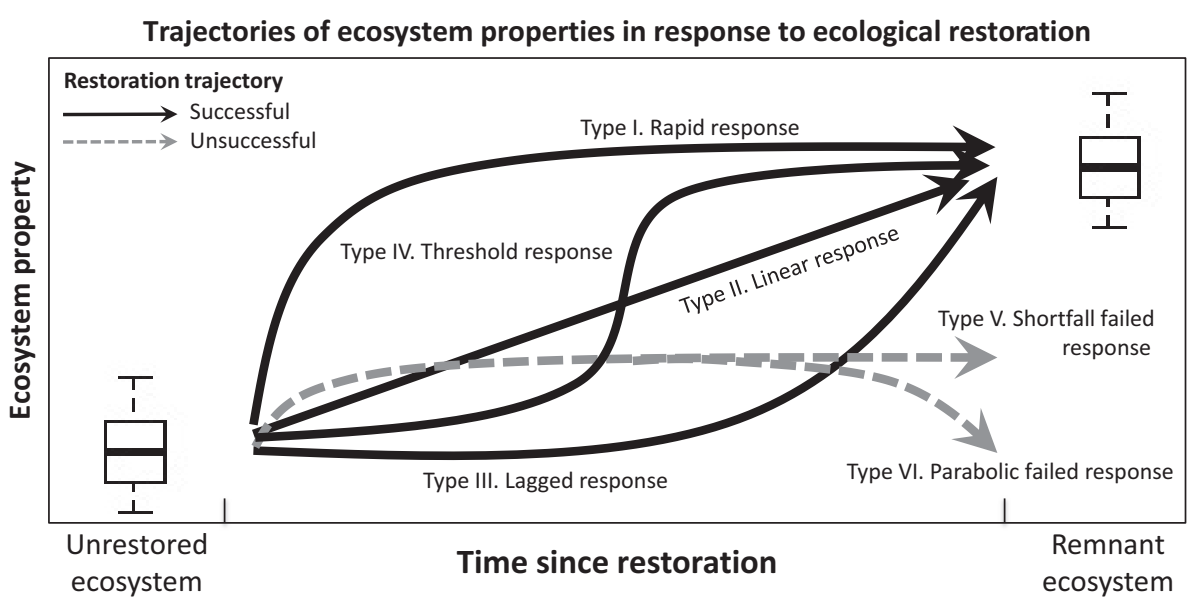

FIG. 1. Conceptual diagram illustrating multiple possible trajectories of ecosystem properties to restoration efforts over time since restoration (Hobbs and Norton 1996, Hobbs and Harris 2001, Suding et al. 2004). The four solid arrows represent successful trajectories that a property may follow from an unrestored level to reach the target level of remnant ecosystems: (I) rapid response, (II) linear response, (III) lagged response, or (IV) threshold response. The response shape may depend on the nature of the property itself or could be affected by management actions. All solid response curves eventually reach values found in remnant ecosystems, but I, II, and IV display marked thresholds where the rate of change is drastically altered. The two dashed arrows represent unsuccessful trajectories where target levels are never attained: (V) shortfall failed response and (VI) parabolic failed response, where restoration efforts were only temporarily effective. This conceptual diagram displays hypothetical unrestored and remnant ecosystem means and distributions using boxplots (on the left and right, respectively). Unrestored ecosystem values are arbitrarily shown as low and remnant ecosystem values as high, but the inverse may be true depending on the ecosystem property. 


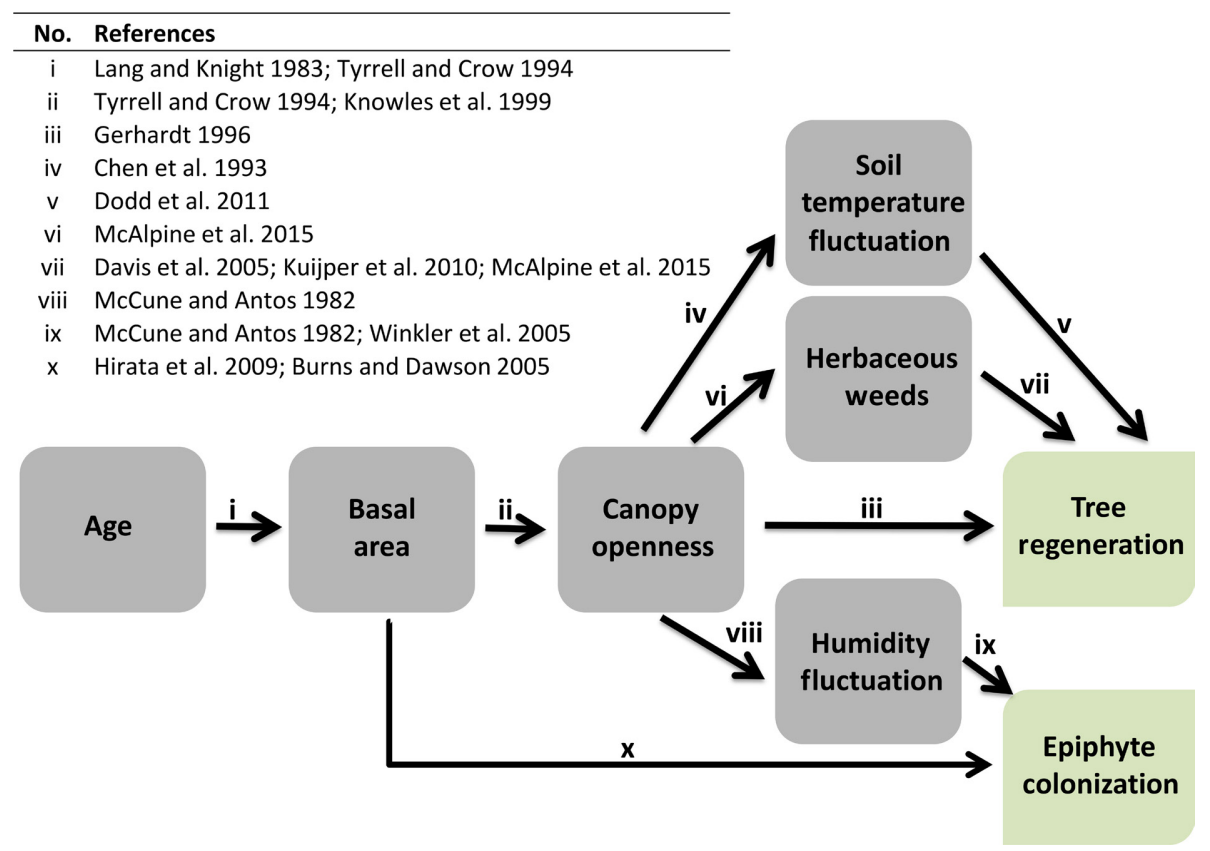

FIG. 2. Hypothesized a priori structural equation model (SEM) illustrating how restored forest properties might influence native tree regeneration and epiphyte colonization. Support for causal relationships are listed by pathway number in the top left. The indicators of restoration success, native tree regeneration and epiphyte colonization, are light gray and their drivers are dark gray. [Colour figure can be viewed at wileyonlinelibrary.com]

favors invasive exotic species (Standish et al. 2001, Suding and Gross 2006, Johnson and Handel 2016). Because urban forests are fragmented, small, and contain high edge-to-area ratios (Smale and Gardner 1999, Overdyck and Clarkson 2012), they are particularly overwhelmed by strong propagule pressure from invasive exotic plant species.

Many degraded urban forests in New Zealand are invaded by exotic deciduous trees. Unlike the native evergreen tree species, these exotics senesce leaves in autumn causing an increase in light availability and larger fluctuations of soil temperatures throughout the winter. These biota-driven changes in environmental conditions facilitate growth of invasive herbaceous plants (McQueen et al. 2006), which would normally go dormant but instead flourish through the mild winters. These herbaceous weeds prevent the regeneration of native tree species (Standish et al. 2001). By restoring a native evergreen canopy, the microclimate may fluctuate less and light availability will be reduced, thereby allowing native shade-tolerant trees and epiphytes to colonize the developing forest.

Our overall objective in this study was to determine the environmental drivers that promote native tree regeneration and epiphyte colonization in restored urban temperate forests (Fig. 2). Forest restoration research often focuses solely on plant community change after planting; here, our objective was to identify the conditions driving that change. To achieve this, we substituted spacefor-time and established a unique chronosequence of forests representing 70 years of forest development following an initial restoration planting. We measured abiotic environmental conditions as well as biotic plant community structure and composition and used structural equation modelling to assess which variables were key drivers of native tree and epiphyte regeneration. Specifically, we asked the following questions: (1) How do biotic and abiotic ecosystem properties change over seven decades in restored urban forests? And (2) what are the key direct and indirect drivers of native tree regeneration and epiphyte colonization?

\section{Materials And Methods}

\section{Study sites}

Our study took place on New Zealand's North Island, which was historically $75 \%$ covered in temperate rainforest but $66 \%$ of which is now cleared for agriculture and silviculture (Nicholls 1980). Data were collected from restored urban forest patches in two cities, Hamilton, population $160,000\left(37.7870^{\circ} \mathrm{S}, 175.2793^{\circ} \mathrm{E}\right)$ and $\mathrm{New}$ Plymouth, population $60,000\left(39.0556^{\circ} \mathrm{S}, 174.0752^{\circ} \mathrm{E}\right)$, about $200 \mathrm{~km}$ apart. Hamilton has an annual mean precipitation of $1,110 \mathrm{~mm}$ with mean minimum and maximum temperatures of $8.7^{\circ} \mathrm{C}$ and $18.9^{\circ} \mathrm{C}$, respectively (data available online), ${ }^{2}$ and $2.1 \%$ indigenous forest cover (Clarkson et al. 2007b). New Plymouth has an annual mean precipitation of $1,400 \mathrm{~mm}$ with mean minimum and maximum temperatures of $10^{\circ}$ and $17.5^{\circ} \mathrm{C}$, respectively

\footnotetext{
${ }^{2}$ http://www.niwa.co.nz/education-and-training/schools/res ources/climate
} 
(see footnote 2), and 8.5\% indigenous forest cover (Clarkson et al. 2007a) of a composition similar to Hamilton. Urban forest patches averaged $2.9 \pm 2.4$ ha $($ mean \pm SD) in size and were $147 \pm 197.97 \mathrm{~m}$ from the nearest forest patch $>0.1$ ha (Appendix S1).

Data was collected from three types of urban forest: unrestored $(n=6)$, restored $(n=27)$, and remnant forest $(n=6)$. Restored sites formed a chronosequence from 3 to 70 years since initial restoration plantings; 36 sites were public and three were private. Chronosequences are spacefor-time substitutions that are useful for understanding the long-term processes of ecological succession (Walker et al. 2010). Unrestored urban forest was defined as a forested area subjected to severe anthropogenic disturbance (e.g., clear-felling or sand mining) before 1960 without further major disturbance or any restoration since, and is now dominated by exotic trees. Remnant forest was defined as a surviving urban fragment of old-growth native forest currently protected from major anthropogenic disturbance. Each urban forest site encompassed three randomly located $10 \times 10 \mathrm{~m}^{2}$ plots, with the constraints that plot edges were never $<1 \mathrm{~m}$ from each other or the edge of the site, or on slopes $>10^{\circ}$. At 12 out of 39 sites at least one plot had to be placed within $1 \mathrm{~m}$ of the forest edge due to the small size or steepness of the forest patch. Five permanent $1-\mathrm{m}^{2}$ subplots were established in each plot.

\section{Data collection}

Woody plants $\geq 2.5 \mathrm{~cm}$ (single and multi-stemmed individuals) diameter at breast height (DBH; $1.4 \mathrm{~m})$ in all three plots at each site were identified to species, classified as native or exotic and the DBH of each stem was recorded. We used these data to compute the basal area of each species in each site. Only native trees were used to compute canopy species richness. Regenerating tree species, defined as trees $<2.5 \mathrm{~cm}$ DBH were identified, classified as native or exotic and tallied by species in one randomly chosen quarter of each plot. Forest community successional status (e.g., early vs. late) for each tree species was assigned according to information found in the restoration plan for Waiwhakareke Natural Heritage Park, a 60-ha New Zealand urban forest restoration project listed in Oldfield et al. (2013).

Herbaceous species were assessed within the subplots by identifying every species rooted within and estimating percent cover by species. Total percent cover could exceed $100 \%$ due to plant overlap in three-dimensional space.

Epiphytes were defined as any vascular plant growing on a tree rooted within a plot. Epiphytes were identified to species using binoculars and tallied by number of host trees they occurred on (Suganuma and Durigan 2015). Total native epiphytes and obligate native epiphytes were used in the analyses; obligate epiphytes are those which must grow on trees (Kirby 2014).

Atmospheric relative humidity $(\mathrm{RH})$ was measured every four hours for 12 months using hygrochrons
(iButton dataloggers model DS1923, Maxim Integrated, San Jose, California, USA). Hygrochrons (one per site) were hung in radiation shields $2 \mathrm{~m}$ above the center subplot in the central plot at each urban forest site. Soil temperature at $10 \mathrm{~cm}$ depth was measured every four hours for 12 months at the center subplot in the outermost two of the three plots at each urban forest site using thermochrons (iButton dataloggers model DS1921G-F5; Maxim Integrated, San Jose, California, USA) (Hubbart et al. 2005). For both RH and soil temperature we computed the standard deviation over one year to represent the temporal fluctuations in these abiotic conditions at each site.

Canopy openness was measured four times (once per season) by taking hemispherical photos of the canopy from $1 \mathrm{~m}$ above the ground in each plot. Resulting images were analyzed with the software Gap Light Analyzer v. 2.0 (Institute of Ecosystem Studies, Millbrook, New York, USA). The average value across the three plots and four seasons was used to quantify site-level canopy openness, an index of light availability.

We also measured a variety of ecosystem properties that were non-impacting, i.e., either did not differ between unrestored and remnant forests, did not change over time in the restored forests, or were not related to tree regeneration or epiphyte colonization. For completeness, we list and describe methods and results for these variables in Appendix S2.

\section{Statistical analyses}

Change in forest ecosystem properties over time.-First, we inspected bivariate plots and fitted generalized linear regression models to evaluate the relationships between restored forest age and either environmental conditions (canopy openness, soil temperature fluctuation, and humidity fluctuation) or plant community attributes (tree basal area, canopy species richness, herbaceous weed cover, native tree regeneration, and epiphyte colonization). We compared environmental conditions and plant community attributes between remnant forests and unrestored forests using Welch's unequal variances $t$ tests $(\alpha=0.05)$. Prior to these tests, canopy openness and humidity were log-transformed. We used the "segmented" package in R (Muggeo 2003) to find breakpoints in the relationships between ecosystem properties and time to test for critical transitions in trajectories of ecosystem properties.

Second, we used nonmetric multidimensional scaling (NMDS) ordination in the vegan package in $\mathrm{R}$ (Oksanen et al. 2015) to quantify differences in plant community composition among unrestored, restored, and remnant forests. Composition was assessed in four vegetation strata: canopy species composition (basal area, $\mathrm{m}^{2} / \mathrm{ha}$ ), native regeneration composition (stems/ha), herbaceous weed composition ( $\%$ cover), and epiphytes (host trees/ ha). One outlier had a very different plant community because it was the only restored site in a salty coastal habitat; this was removed from all NMDS analyses. Prior to fitting the ordination models, species abundance data 
were square-root transformed and standardized using a Wisconsin double relativization (Gauch 1982). Environmental variables were log transformed and illustrated as vectors on the NMDS plots if they were significantly correlated with the ordination axes $(\alpha=0.05)$. We tested for differences in plant community composition between unrestored and remnant forests with PERMANOVA (Anderson 2001), using the vegan package in $\mathrm{R}$ (Oksanen et al. 2015).

Constraints on tree regeneration and epiphyte colonization.-We used structural equation modelling with the $\mathrm{R}$ package piecewiseSEM (Lefcheck 2015) to determine the direct and indirect drivers of native tree regeneration and epiphyte colonization. This multivariate approach tests hypothesized relationships among a system of state variables. Using theory and empirical data, we developed an a priori model that we believed to be the most plausible causal structure of the factors that constrain native tree regeneration and epiphyte colonization in restored forests (Fig. 2). We hypothesized that age and basal area would be indirect drivers of native tree regeneration and obligate epiphyte colonization (Lang and Knight 1983, Tyrrell and Crow 1994) and that basal area would mediate the indirect effect of age on canopy openness (Tyrrell and Crow 1994, Knowles et al. 1999). We predicted that canopy openness would have direct effects on native tree regeneration (Gerhardt 1996, Olesen and Madsen 2008, Bertacchi et al. 2016), soil temperature fluctuation (Chen et al. 1993), humidity fluctuation (McCune and Antos 1982), and herbaceous weed cover (McAlpine et al. 2015). Our model hypothesized that soil temperature fluctuation (Dodd et al. 2011) and herbaceous weed cover would directly constrain native tree regeneration (Davis et al. 2005, Kuijper et al. 2010, Dodd et al. 2011, Overdyck and Clarkson 2012, McAlpine et al. 2015, Yelenik 2016), while basal area (Burns and Dawson 2005, Hirata et al. 2009) and humidity fluctuation (McCune and Antos 1982, Callaway et al. 2002, Winkler et al. 2005, Zotz and Bader 2009) would directly constrain epiphyte colonization.

Prior to analysis, variables were log-transformed to linearize relationships, except for soil temperature standard deviation and humidity standard deviation. All variables were also scaled to unit variance, except for epiphyte density and richness, which were Poisson distributed. We fit two models using the same a priori model structure (Fig. 2): one for the density of tree regeneration and epiphyte colonization, and one for species richness of tree regeneration and epiphyte colonization. We used a Gaussian distribution to model regeneration density and richness, but we used a quasipoisson distribution to model epiphyte density and richness because these Poisson-distributed variables were over-dispersed (Wells and O'Hara 2013). Because the model included both Gaussian and Poisson error distributions, we only report the unstandardized coefficients. Model fit was assessed using Fisher's $C$ statistic (Grace 2006, Lefcheck 2015), where good-fitting models yield small $C$ statistics and
$P$ values $>0.05$. Poor fitting models were improved by removing nonsignificant pathways and variables that were not significantly related to the response variables.

We tested whether the effects of direct drivers of native plant regeneration differed between the two cities by fitting separate ANCOVA models. We added city as a fixed effect to test for differences in the direct effects of microclimate, weeds, and basal area on plant regeneration. For example, tree regeneration density was modelled as a function of weed cover, city, and a weed cover $\times$ city interaction, where the main effect of city tests for a shift in intercept, whereas the interaction tests for a difference in slope between cities.

\section{RESUlts}

\section{Change in forest ecosystem properties over time}

Unrestored forests contained marginally less tree basal area than remnant forests $\left(36 \mathrm{~m}^{2} /\right.$ ha vs. $93 \mathrm{~m}^{2} / \mathrm{ha}$, $t_{6.0}=-2.1664, P=0.0734$, Fig. 3A) but had higher canopy openness $\left(13 \%\right.$ vs. $3 \%, t_{9.3}=5.9372, P=0.0002$, Fig. 3B). In restored forests, tree basal area increased linearly over the 70-yr time span of the chronosequence (Fig. 3A), contrasting with canopy openness, which dropped rapidly (Fig. 3B). A breakpoint in canopy openness occurred at approximately 18 years (Appendix S3), when light transmittance decreased to levels detected in remnant forests.

There was no difference in humidity fluctuation in unrestored and remnant forests $\left(t_{7.0}=1.9312, P=0.0945\right)$, while in restored forests, fluctuations in humidity decreased rapidly with age (Fig. 3C). A breakpoint in humidity fluctuation occurred at approximately 23 years (Appendix S3), after which humidity levels were consistently more stable. Unrestored forest soil temperatures fluctuated marginally more than remnant forest soils ( $t_{8.5}=2.1387, P=0.0626$, Fig. 3D). In restored forests, soil temperature fluctuations lessened with age, and became consistently stable at approximately 21 years (Appendix S3).

Herbaceous weed cover in unrestored forests was greater than in remnant forests $\left(37 \%\right.$ vs. $5 \%, t_{8.7}=3.8366$, $P=0.0042$, Fig. 3E). Weed cover in restored forests declined rapidly from $75 \%$ in the youngest planting to $1 \%$ at approximately 18 years, where a breakpoint occurred (Appendix S3). Herbaceous weed community composition differed between unrestored and remnant forests (PERMANOVA, $F_{10,1}=3.1103, P=0.016$, Appendix S4). Restored forest weed compositions were least similar to one another between 6 and 11 years post-planting.

Canopy species richness differed significantly between unrestored and remnant forests $\left(t_{8.9}=-3.0812\right.$, $P=0.0133)$, and increased linearly over time in restored forests (Fig. 3F). By 70 years after restoration, the restored forest canopy had twice as many tree species as unrestored forest (14 vs. 7.3, Fig. 3F). Canopy composition differed between unrestored and remnant forests 

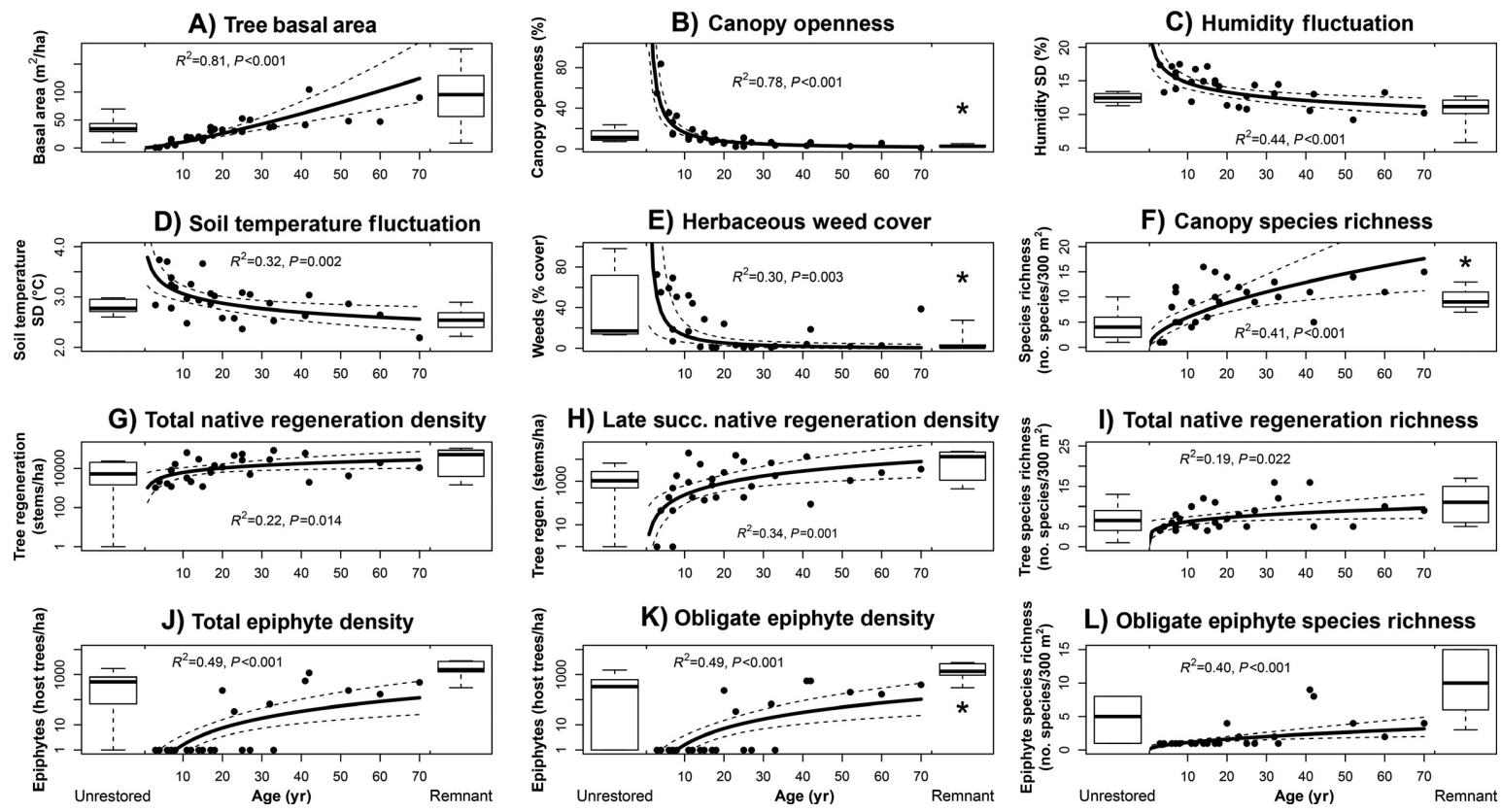

FIG. 3. Environmental conditions and plant community attributes in restored forests over time (central section of each bivariate plot), compared with unrestored and remnant forests (boxplots to left and right, respectively). Total native tree species regeneration, late-successional tree regeneration density, total epiphyte density, and obligate epiphyte density have $y$-axes shown in log-scale. Boxplots represent 25th, 50th, and 75th percentiles and whiskers extend to data extremes. Scatterplot points represent restored sites; the solid lines represent the fitted values from a linear regression model on log-transformed data, and the dashed lines represent $95 \%$ confidence intervals. Asterisks indicate a significant difference between unrestored and remnant forests $(\alpha=0.05)$

(PERMANOVA, $F_{10,1}=1.9676, P<0.005$, Appendix S4). The oldest restored forests had canopy compositions most similar to remnant forest.

There was a marginal difference in total native tree regeneration density between unrestored and remnant forests, with five times more native trees regenerating in remnant forests (9422 stems/ha vs. 50244 stems/ha, $t_{5.5}=-2.190, P=0.0749$, Fig. $\left.3 \mathrm{G}\right)$. Total native tree regeneration density in restored forests increased over time, becoming similar to remnant forests within the first few decades (Fig. 3G). Regeneration density of late successional native trees followed a similar pattern and was marginally greater in remnant forest than in unrestored forest $\left(t_{5.6}=-2.3636, P=0.0591\right.$, Fig. $\left.3 \mathrm{H}\right)$, however it was generally much lower than total regeneration density, and comprised little of the total regeneration in the youngest restored forests (Fig. 3G, H; Appendix S5). Total native tree regeneration species richness was not different between unrestored and remnant forest $\left(t_{9.8}=-1.6051, P=0.14\right)$, but did increase with restoration age (Fig. 3I). Native tree regeneration in unrestored forests had a different composition to those of remnant forests (PERMANOVA, $F_{10,1}=1.7149$, $P=0.043$; Appendix S4). Only $29 \%$ of tree species regenerating in unrestored forest were late successional species, compared with $58 \%$ in remnant forest, where environmental conditions were more stable.

Total epiphyte density was marginally greater in remnant forests compared with unrestored forests $\left(t_{7.5}=-2.2761, P=0.0545\right.$, Fig. 3J). Epiphytes were absent in young restored forests, but colonization began at approximately 20 years after restoration and total densities subsequently appeared to be similar to remnant site levels by approximately 40 years (Fig. 3J). Obligate epiphyte density was significantly greater in remnant forest than unrestored $\left(t_{7.7}=-2.3275, P=0.04976\right.$, Fig. $\left.3 \mathrm{~K}\right)$ and obligate epiphyte species richness was marginally greater in remnant forest $\left(t_{8.6}=-2.0521, P=0.0717\right.$, Fig. 3L). Obligate epiphyte species were also absent in sites $<20$ years old, but after that there were on average 2.3 species growing in restored forest sites (Fig. 3L). Epiphyte community composition in remnant forest was dissimilar to that of unrestored forests (PERMANOVA, $F_{10,1}=3.9031, P=0.005 ;$ Appendix S4).

\section{Constraints on tree regeneration and epiphyte colonization}

The a priori structural equation model of native tree regeneration and epiphyte density did not fit the data well (Fisher's $C=53.99$, df $=36, P=0.027$, Fig. 2). We removed the nonsignificant pathway from canopy openness to native tree regeneration (pathway iii, Fig. 2). This new model fit the data well (Fisher's $C=50.46$, $\mathrm{df}=38, P=0.085$, Fig. $4 \mathrm{~A}$ ), explaining $40 \%$ of the variation in native tree regeneration density and $64 \%$ of the variation in epiphyte colonization density. The final model also explained significant variation in herbaceous 


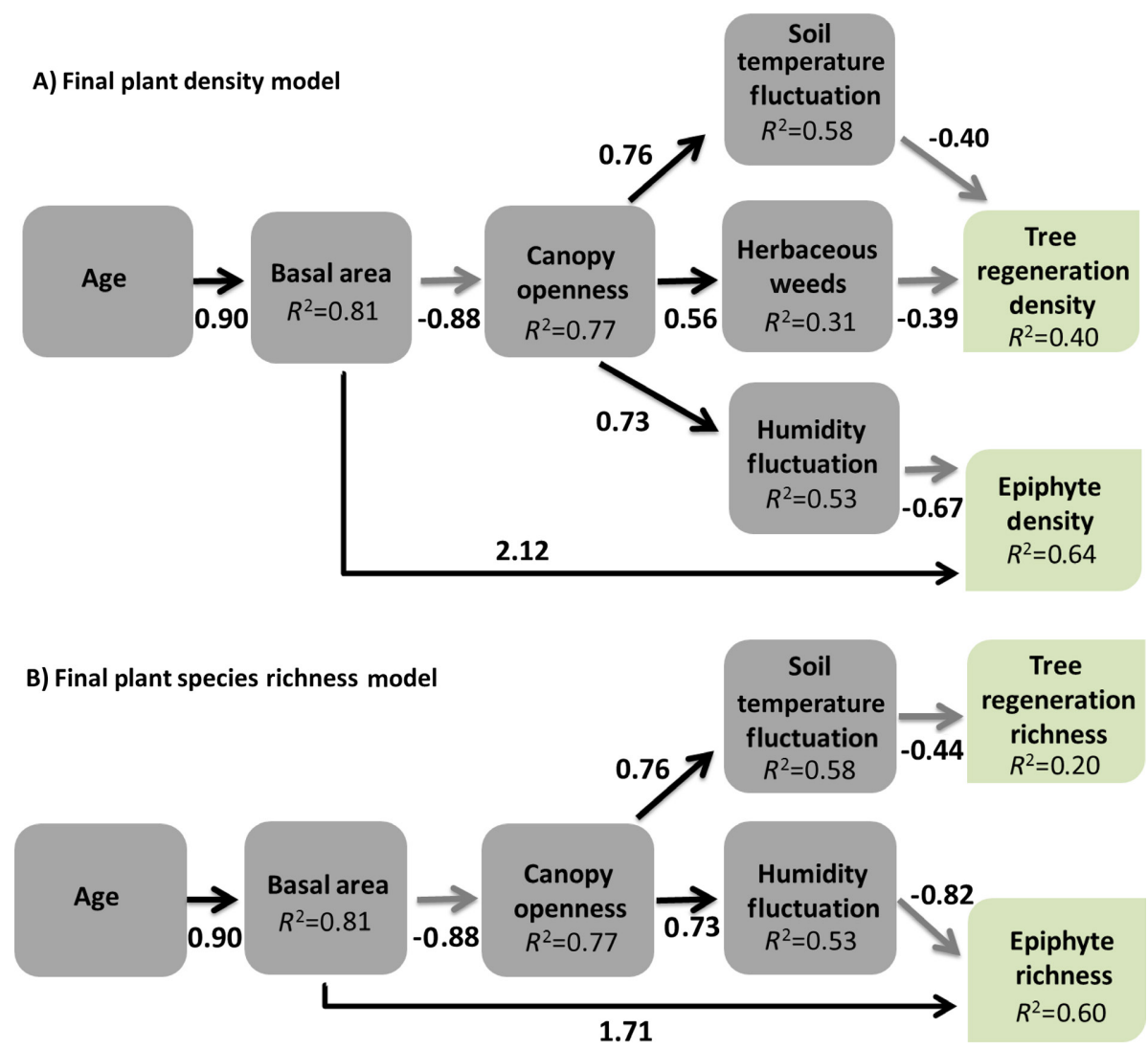

FIG. 4. The two final structural equation models (SEMs), illustrating drivers of native tree regeneration and epiphyte colonization. The top model (A) illustrates drivers of plant density and the lower model (B) illustrates drivers of plant species richness. The indicators of restoration success, native tree regeneration and epiphyte colonization, are shown in light gray, and their drivers in dark gray. Values by arrows are unstandardized path coefficients. An $R^{2}$ value is shown in the box of each response variable. For clarity, positive pathways are black and negative pathways are gray. [Colour figure can be viewed at wileyonlinelibrary. com]

weed cover $(31 \%)$, soil temperature fluctuation $(58 \%)$, humidity fluctuation (53\%), canopy openness $(77 \%)$, and basal area ( $81 \%$; Fig. 4A).

The final plant density model indicates that native tree regeneration densities were highest where herbaceous weed cover and soil temperature fluctuation were lowest (Fig. 4A). Importantly, native tree regeneration density was not directly related to canopy openness, but rather was indirectly related to canopy openness through the mediating factors of herbaceous weed cover and soil temperature fluctuation. High epiphyte density was related to smaller fluctuations in humidity and greater tree basal area.

The a priori structural equation model of native tree regeneration and epiphyte species richness did not fit the data well (Fisher's $C=65.18, \mathrm{df}=36, P=0.002$; Fig. 2). We removed the nonsignificant pathway from canopy openness to native tree regeneration (pathway iii, Fig. 2) and removed herbaceous weed cover from the model. This new model fit the data well (Fisher's $C=31.67$, df $=28, P=0.288$; Fig. 4B) and explained significant variation in tree regeneration species richness $(20 \%)$ and species richness of epiphytes (60\%; Fig. 4B).
The final species richness model indicates that native tree regeneration richness was highest where soil temperature fluctuation was lowest, which was related to canopy openness (Fig. 4B). High epiphyte richness was related to smaller fluctuations in humidity and greater tree basal area.

Direct effects on native plant regeneration did not differ substantially between the two cities (Appendix S6). We detected minor differences for a few relationships, such as a shift in intercept or a shift in both intercept and slope between the two cities in the relationships between epiphytes and tree basal area (Appendix S6), but all other relationships remained unchanged. Importantly, the sign and meaning of the relationships were the same across both cities, and the effects of microclimate and weeds remained significant.

\section{DisCUSSION}

The results of this restoration chronosequence improve our understanding of the temporal dynamics that occur in restored forests over decadal time scales. We found that many ecosystem properties change over time as 
restored forests mature, and a few key properties drive restoration success. Specifically, our structural equation model (SEM) demonstrated that two indicators of successful forest restoration, native tree regeneration and epiphyte colonization, were constrained by fluctuating microclimate and exotic herbaceous weeds. These factors were functions of changes in forest structure and light availability, both of which changed predictably as the forests aged. A critical threshold was reached at approximately 20 years after the initial restoration planting, when conditions became suitable for the spontaneous regeneration of native trees and epiphytes.

Ecosystem properties of restored forests followed different recovery trajectories (Fig. 1). The historic expectation in terrestrial habitat management is a linear response to system perturbation, and threshold responses are not yet well understood (Suding and Hobbs 2009). We observed linear rates of change, rapid changes that plateaued quickly, and threshold responses. Understanding the nature of these responses is important for management because restored forest properties are inexorably linked (Dodd et al. 2011). Importantly, we observed that reaching a threshold in one ecosystem property can trigger sudden changes in other conditions that promote natural processes, such as regeneration, that are necessary for long-term forest development.

Many critical changes occurred at approximately 20 years of forest development, when basal area increased to an average $27 \pm 2.8 \mathrm{~m}^{2} / \mathrm{ha}$ (mean $\pm \mathrm{SE}$ ). Trajectories of four ecosystem properties in particular were altered at this level of basal area: light availability reached a low point, herbaceous weed cover was reduced, atmospheric relative humidity beneath the canopy was stabilized, and soil temperature was stabilized (Appendix S3). Forest structure and composition can be dynamic during this early stand initiation phase of forest dynamics (Oliver and Larson 1990). Time since restoration is a main driver of success (Crouzeilles et al. 2016), and recent research suggests that critical changes in restored ecosystem conditions occur within 15-20 years after the initiation of forest restoration. For example, Johnson and Handel (2016) found significantly more native regeneration and more complex forest structure in 15-20 years old restored sites than in unrestored sites. Shoo et al. (2015) found that species richness increased within 20 years in tropical rainforest restoration plantings and the richness included important elements of forest structure such as vines and epiphytes. Structural complexity and native regeneration increase biodiversity (Burghardt et al. 2009, Threlfall et al. 2016), which increases resilience to perturbation (Walker 1995, Dodd et al. 2011, Oakley and Knox 2012), thereby minimizing the need for further restoration intervention. Isolation of urban forest patches may have hindered seed dispersal of some native plant species (Overdyck and Clarkson 2012, Taylor and Burns 2015). Such isolation could ultimately limit regeneration success regardless of whether the required set of environmental conditions arise within the developing forests (Robinson and Handel 1993, Lehvävirta and Rita 2002). In cases of extreme seed dispersal limitation in some urban forests, propagules will need to be introduced by practitioners to promote native plant colonization.

In our study, the key direct drivers of native tree regeneration were herbaceous weeds and microclimatic fluctuations. Herbaceous weeds limit the establishment and survival of native tree seedlings (Davis et al. 2005, Overdyck and Clarkson 2012, George and Bazzaz 2014, McAlpine et al. 2015, Yelenik 2016). Many exotic weeds are nutrient-demanding and will compete aggressively for belowground resources in forests (Gilliam 2006, Peltzer et al. 2009, Yelenik 2016). Some also have specific symbiotic mycorrhizae that can cause advantage in uptake capability (Cornelissen et al. 2001) or have antifungal exudates that disrupt native tree mycorrhizal associations (Stinson et al. 2006). Whether shade-tolerant or light-demanding, exotic herbaceous weeds compete aggressively for light reaching the forest floor (Neufeld and Young 2014). Despite a significant decrease in weed cover as sites grew older, our oldest site contained unexpectedly high cover (38\%) of a problematic shade-tolerant weed (Tradescantia fluminensis Vell.), which has been known to reduce native tree regeneration if present in great enough biomass (Standish et al. 2001).

Native tree regeneration was also directly regulated by temperature fluctuations in the soil. Soil temperatures can play a pivotal role in both tree regeneration density and diversity by triggering germination (Vázquez-Yanes and Orozco-Segovia 1982) and dictating growth rate (Heninger and White 1974). Both soil frost (Goulet 1995) and excessive heat (Lopushinsky and Max 1990) can cause seedling mortality. Tree seedlings differ by species in their optimal soil temperature for growth (Heninger and White 1974). Early successional species are adapted to larger fluctuations in conditions (Bazzaz 1979), explaining why they comprise the majority of seedlings early in the chronosequence. The difference between unrestored and remnant forest regeneration composition suggests that a subset of species, likely many late successional native trees, cannot tolerate conditions found in unrestored forests.

Epiphyte colonization was triggered by reaching critical thresholds in microclimatic stability and substrate availability (Fig. 1). Taylor and Burns (2015) proposed three stages of epiphyte community development: (1) host trees are devoid of epiphytes due to lack of sufficient architectural characteristics, (2) adult host trees acquire epiphytes and continue to do so into maturity, and (3) epiphyte communities experience decline due to host tree mortality. We observed the first two stages within the chronosequence we studied. Stage one lasted for approximately 20 years, and stage two was triggered when epiphytes began to colonize forests with basal area of $\sim 27 \mathrm{~m}^{2} /$ ha and when humidity stabilized under the forest canopy.

Epiphytes can be particularly sensitive to desiccation because their roots are exposed as they cling to their host 
trees (Palmer et al. 1997, León-Vargas et al. 2006). Epiphyte species stratify themselves along a ground-tocanopy gradient, where those that are more sensitive to evaporative water loss colonize closer to the shaded forest floor (Hietz and Briones 1998, Sporn et al. 2010). The development of the tree canopy creates an increasing range of suitable conditions for epiphytes, facilitating greater species diversity, especially high in the canopy (León-Vargas et al. 2006, Reid et al. 2016). Additionally, as epiphytes accumulate, their own biomass creates further microclimatic buffering, facilitating greater epiphytic colonization (Reid et al. 2016). Other studies have found that restored forests often support greater diversity and density of epiphytes compared to unrestored or spontaneously regenerated forests (Kanowski et al. 2003, Reid et al. 2016). In our study, greater density and richness was found in stands with smaller fluctuations in humidity and the largest trees (Burns and Dawson 2005, Burns 2008, Hirata et al. 2009).

Management actions promoting the conditions that allow for native plant regeneration are required to ensure that initial planting efforts lead to resilient and enduring forests. Our results suggest that late successional plant establishment in restored urban forests is constrained by herbaceous weeds and microclimatic instability, both of which are driven by light availability. The relationships we observed between direct drivers and native plant regeneration were qualitatively similar between the two cities (Appendix S6). We expect to observe natural variation in the strength and importance of some of these relationships across different cities and regions, but the overall patterns should be robust and, within reason, can be generalized to other global contexts. To succeed in restoring urban forests, we recommend management actions that promote rapid canopy closure. For example, given a finite supply of native tree seedlings, it is better to plant seedlings at high densities over small areas rather than low densities across large areas. Many ecosystem properties change predictably over time as canopies develop, allowing management decisions to be planned on decadal timescales. Given the timescales at which forests dynamics operate, local governments that manage urban forests should adopt long-term planning strategies similar to those of forestry operations. This will be challenging given the rapid turnover of political offices.

Initial restoration plantings are often followed by further site management, such as enrichment planting of late successional species. These enrichment plantings are undertaken to hasten forest development after the initial planting (Martínez-Garza and Howe 2003, Schulze 2008), but more work is needed to evaluate the survival of enrichment seedlings that are planted early on, given that the conditions in the chronosequence were not optimal until 20 years after planting. Microclimate conditions are difficult to manipulate directly, but tree seedling survival could be enhanced by coinciding enrichment planting with herbaceous weed control until the canopy is sufficiently closed.
Some indicators of long-term forest restoration success, such as colonization of the canopy by epiphytes, will be constrained by the size of the trees (Burns and Dawson 2005, Hirata et al. 2009). A minimum target basal area of $27 \mathrm{~m}^{2} /$ ha could provide guidance for where to cultivate tree seedlings or epiphytes, especially in urban sites that are chronically limited by adequate propagule dispersal (Overdyck and Clarkson 2012). The restoration of natural areas within cities is a critically important objective for urban land managers to reconnect people to the ecosystems that sustain life on Earth (Pickett et al. 2011, Standish et al. 2013), and our results provide guidance for how to restore resilient urban forests efficiently and successfully.

\section{ACKNOWLEDGMENTS}

We thank owners of three private sites for granting land access and also express gratitude to our field assistants P. Balle, M. Brown, R. Bylsma, M. Cederman, T. Cornes, M. Cummins, E. E. Elliot, B. Finlay, D. Fitzpatrick, C. Foster, E. Grierson, O. Henwood, C. Hill, A. Hughes, C. L. Kirby, K. KramerWalter, M. Lelarge, T. Moore, R. E. Nepia, A. Purcell, M. Riviere, L. Schneider, L. van Schalkwyk, and L. A. Wallace. Funding was provided by the University of Waikato, the Environmental Research Institute, the New Zealand Federation of Graduate Women, the Wellington Botanical Society, the Puke Ariki George Mason Charitable Trust, the New Zealand Plant Protection Society, and a Ministry of Business, Innovation and Employment grant (UOWX1601) from the New Zealand government.

\section{Literature Cited}

Anderson, M. J. 2001. A new method for non-parametric multivariate analysis of variance. Austral Ecology 26:32-46.

Bazzaz, F. A. 1979. The physiological ecology of plant succession. Annual Review of Ecology and Systematics 10:351-371.

Bertacchi, M. I. F., N. T. Amazonas, P. H. S. Brancalion, G. E. Brondani, A. C. S. de Oliveira, M. A. R. de Pascoa, and R. R. Rodrigues. 2016. Establishment of tree seedlings in the understory of restoration plantations: natural regeneration and enrichment plantings. Restoration Ecology 24:100-108.

Boudreault, C., S. Gauthier, and Y. Bergeron. 2000. Epiphytic lichens and bryophytes on Populus tremuloides along a chronosequence in the southwestern boreal forest of Québec, Canada. Bryologist 103:725-738.

Brown, N. 1993. The implications of climate and gap microclimate for seedling growth conditions in a Bornean lowland rain forest. Journal of Tropical Ecology 9:153-168.

Bullock, J. M., J. Aronson, A. C. Newton, R. F. Pywell, and J. Rey-Benayas. 2011. Restoration of ecosystem services and biodiversity: conflicts and opportunities. Trends in Ecology and Evolution 26:541-549.

Burghardt, K. T., D. W. Tallamy, and W. Gregory Shriver. 2009. Impact of native plants on bird and butterfly biodiversity in suburban landscapes. Conservation Biology 23: 219-224.

Burns, K. C. 2008. Meta-community structure of vascular epiphytes in a temperate rainforest. Botany 86:1252-1259.

Burns, K. C., and J. Dawson. 2005. Patterns in the diversity and distribution of epiphytes and vines in a New Zealand forest. Austral Ecology 30:891-899.

Callaway, R. M., K. O. Reinhart, G. W. Moore, D. J. Moore, and S. C. Pennings. 2002. Epiphyte host preferences and host 
traits: mechanisms for species-specific interactions. Oecologia 132:221-230.

Chen, J., J. F. Franklin, and T. A. Spies. 1993. Contrasting microclimates among clearcut, edge, and interior of oldgrowth Douglas-fir forest. Agricultural and Forest Meteorology 63:219-237.

Clarkson, B. D., P. M. Wehi, and L. K. Brabyn. 2007a. Bringing back nature into cities: urban land environments, indigenous cover, and urban restoration. Research Report 52. Centre for Biodiversity and Ecology, University of Waikato, Hamilton, New Zealand.

Clarkson, B. D., P. M. Wehi, and L. K. Brabyn. 2007b. A spatial analysis of indigenous cover patterns and implications for ecological restoration in urban centres, New Zealand. Urban Ecosystems 10:441-457.

Cornelissen, J. H. C., R. Aerts, B. Cerabolini, M. J. A. Werger, and M. van der Heijden. 2001. Carbon cycling traits of plant species are linked with mycorrhizal strategy. Oecologia 129:611-619.

Crouzeilles, R., M. Curran, M. S. Ferreira, D. B. Lindenmayer, C. E. V. Grelle, and J. M. Rey Benayas. 2016. A global meta-analysis on the ecological drivers of forest restoration success. Nature Communications 7. https://doi.org/10.1038/ ncomms11666

Davis, M. A., L. Bier, E. Bushelle, C. Diegel, A. Johnson, and B. Kujala. 2005. Non-indigenous grasses impede woody succession. Plant Ecology 178:249-264.

Dobbs, C., F. J. Escobedo, and W. C. Zipperer. 2011. A framework for developing urban forest ecosystem services and goods indicators. Landscape and Urban Planning 99:196-206.

Dodd, M., G. Barker, B. Burns, R. Didham, J. Innes, C. King, M. Smale, and C. Watts. 2011. Resilience of New Zealand indigenous forest fragments to impacts of livestock and pest mammals. New Zealand Journal of Ecology 35:83-95.

Ehrenfeld, J. G., and L. A. Toth. 1997. Restoration ecology and the ecosystem perspective. Restoration Ecology 5:307-317.

Gauch, H. G. 1982. Multivariate analysis in community ecology. Cambridge University Press, Cambridge, UK.

George, L. O., and F. A. Bazzaz. 2014. The herbaceous layer as a filter determining spatial pattern in forest tree regeneration. Pages 265-282 in F. S. Gilliam and M. R. Roberts, editors. The herbaceous layer in forests of Eastern North America. Oxford University Press, New York, New York, USA.

Gerhardt, K. 1996. Effects of root competition and canopy openness on survival and growth of tree seedlings in a tropical seasonal dry forest. Forest Ecology and Management 82:33-48.

Gilliam, F. S. 2006. Response of the herbaceous layer of forest ecosystems to excess nitrogen deposition. Journal of Ecology 94:1176-1191.

Goulet, F. 1995. Frost heaving of forest tree seedlings: a review. New Forests 9:67-94.

Grace, J. B. 2006. Structural equation modeling and natural systems. Cambridge University Press, New York, New York, USA.

Groffman, P. M., et al. 2016. Moving towards a new urban systems science. Ecosystems:1-6. https://doi.org/10.1007/ s10021-016-0053-4

Heninger, R. L., and D. P. White. 1974. Tree seedling growth at different soil temperatures. Forest Science 20:363-367.

Hietz, P., and O. Briones. 1998. Correlation between water relations and within-canopy distribution of epiphytic ferns in a Mexican cloud forest. Oecologia 114:305-316.

Hirata, A., T. Kamijo, and S. Saito. 2009. Host trait preferences and distribution of vascular epiphytes in a warm-temperate forest. Plant Ecology 201:247-254.

Hobbs, R. J., and J. A. Harris. 2001. Restoration ecology: repairing the earth's ecosystems in the new millennium. Restoration Ecology 9:239-246.
Hobbs, R. J., and D. A. Norton. 1996. Towards a conceptual framework for restoration ecology. Restoration Ecology 4:93-110.

Hobbs, R. J., E. Higgs, and J. A. Harris. 2009. Novel ecosystems: implications for conservation and restoration. Trends in Ecology and Evolution 24:599-605.

Hubbart, J., T. Link, C. Campbell, and D. Cobos. 2005. Evaluation of a low-cost temperature measurement system for environmental applications. Hydrological Processes 19:1517-1523.

Johnson, L. R., and S. N. Handel. 2016. Restoration treatments in urban park forests drive long-term changes in vegetation trajectories. Ecological Applications 26:940-956.

Kanowski, J., C. P. Catterall, G. W. Wardell-Johnson, H. Proctor, and T. Reis. 2003. Development of forest structure on cleared rainforest land in eastern Australia under different styles of reforestation. Forest Ecology and Management 183:265-280.

Kirby, C. L. 2014. Field guide to New Zealand's epiphytes, vines and mistletoes. The Environmental Research Institute, University of Waikato, Hamilton, New Zealand.

Knowles, R. L., G. C. Horvath, M. A. Carter, and M. F. Hawke. 1999. Developing a canopy closure model to predict overstorey/understorey relationships in Pinus radiata silvopastoral systems. Pages 109-119 in D. Auclair and C. Dupraz, editors. Agroforestry for sustainable land-use fundamental research and modelling with emphasis on temperate and Mediterranean applications: selected papers from a workshop held in Montpellier, France, 23-29 June 1997. Springer Netherlands, Dordrecht, The Netherlands.

Kuijper, D. P. J., J. P. G. M. Cromsigt, B. Jędrzejewska, S. Miścicki, M. Churski, W. Jędrzejewski, and I. Kweczlich. 2010. Bottom-up versus top-down control of tree regeneration in the Białowieża Primeval Forest, Poland. Journal of Ecology 98:888-899.

Lang, G. E., and D. H. Knight. 1983. Tree growth, mortality, recruitment, and canopy gap formation during a 10-year period in a tropical moist forest. Ecology 64:1075-1080.

Laughlin, D. C. 2014. Applying trait-based models to achieve functional targets for theory-driven ecological restoration. Ecology Letters 17:771-784.

Laughlin, D. C., J. D. Bakker, M. L. Daniels, M. M. Moore, C. A. Casey, and J. D. Springer. 2008. Restoring plant species diversity and community composition in a Ponderosa Pinebunchgrass ecosystem. Plant Ecology 197:139-151.

Lefcheck, J. S. 2015. piecewiseSEM: Piecewise structural equation modelling in $\mathrm{r}$ for ecology, evolution, and systematics. Methods in Ecology and Evolution 7:573-579.

Lehvävirta, S., and H. Rita. 2002. Natural regeneration of trees in urban woodlands. Journal of Vegetation Science 13:57-66.

León-Vargas, Y., S. Engwald, and M. C. F. Proctor. 2006. Microclimate, light adaptation and desiccation tolerance of epiphytic bryophytes in two Venezuelan cloud forests. Journal of Biogeography 33:901-913.

Lopushinsky, W., and T. A. Max. 1990. Effect of soil temperature on root and shoot growth and on budburst timing in conifer seedling transplants. New Forests 4:107-124.

Martínez-Garza, C., and H. F. Howe. 2003. Restoring tropical diversity: beating the time tax on species loss. Journal of Applied Ecology 40:423-429.

McAlpine, K. G., S. L. Lamoureaux, and I. Westbrooke. 2015. Ecological impacts of ground cover weeds in New Zealand lowland forests. New Zealand Journal of Ecology 39:50-60.

McCauley, L. A., D. G. Jenkins, and P. F. Quintana-Ascencio. 2012. Reproductive failure of a long-lived wetland tree in urban lands and managed forests. Journal of Applied Ecology 50:25-33. 
McCune, B., and J. A. Antos. 1982. Epiphyte communities of the Swan Valley, Montana. Bryologist 85:1-12.

McQueen, J. C., W. C. Tozer, and B. D. Clarkson. 2006. Consequences of alien $\mathrm{N}_{2}$-fixers on vegetation succession in New Zealand. Pages 295-304 in R. B. Allen and W. G. Lee, editors. Biological invasions in New Zealand. Springer, Berlin, Germany.

Miller, B. P., et al. 2016. A framework for the practical science necessary to restore sustainable, resilient, and biodiverse ecosystems. Restoration Ecology. https://doi.org/10.1111/ rec. 12475

Muggeo, V. M. R. 2003. Estimating regression models with unknown break-points. Statistics in Medicine 22: 3055-3071.

Neufeld, H. S., and D. R. Young. 2014. Ecophysiology of the herbaceous layer in temperate deciduous forests. Pages 15-37 in F. S. Gilliam, editor. The herbaceous layer in forests of eastern North America. Oxford University Press, New York, New York, USA.

Nicholls, J. L. 1980. The past and present extent of New Zealand's indigenous forests. Environmental Conservation 7:309-310.

Oakley, C. A., and J. S. Knox. 2012. Plant species richness increases resistance to invasion by non-resident plant species during grassland restoration. Applied Vegetation Science $16: 21-28$.

Oishi, Y., and H. Doei. 2015. Changes in epiphyte diversity in declining forests: implications for conservation and restoration. Landscape and Ecological Engineering 11:283-291.

Oksanen, J., F. G. Blanchet, R. Kindt, P. Legendre, P. R. Minchin, R. B. O'hara, G. L. Simpson, P. Solymos, M. H. H. Stevens, and H. Wagner. 2015. Vegan:community ecology package. http://CRAN.R-project.org/package=vegan $\mathrm{R}$ package version $2.2-1$

Oldfield, E. E., R. J. Warren, A. J. Felson, and M. A. Bradford. 2013. FORUM: Challenges and future directions in urban afforestation. Journal of Applied Ecology 50:1169-1177.

Oldfield, E. E., et al. 2015. Growing the urban forest: tree performance in response to biotic and abiotic land management. Restoration Ecology 23:707-718.

Olesen, C. R., and P. Madsen. 2008. The impact of roe deer (Capreolus capreolus), seedbed, light and seed fall on natural beech (Fagus sylvatica) regeneration. Forest Ecology and Management 255:3962-3972.

Oliver, C. D., and B. C. Larson. 1990. Forest stand dynamics. McGraw-Hill, New York, New York, USA.

Overdyck, E., and B. D. Clarkson. 2012. Seed rain and soil seed banks limit native regeneration within urban forest restoration plantings in Hamilton City, New Zealand. New Zealand Journal of Ecology 36:1-14.

Overdyck, E., B. D. Clarkson, D. C. Laughlin, and C. E. C. Gemmill. 2013. Testing broadcast seeding methods to restore urban forests in the presence of seed predators. Restoration Ecology 21:763-769.

Palmer, M. A., R. F. Ambrose, and N. L. Poff. 1997. Ecological theory and community restoration ecology. Restoration Ecology 5:291-300.

Peltzer, D. A., P. J. Bellingham, H. Kurokawa, L. R. Walker, D. A. Wardle, and G. W. Yeates. 2009. Punching above their weight: low-biomass non-native plant species alter soil properties during primary succession. Oikos 118:1001-1014.

Pickett, S. T. A., et al. 2011. Urban ecological systems: Scientific foundations and a decade of progress. Journal of Environmental Management 92:331-362.

Reid, J. L., J. M. Chaves-Fallas, K. D. Holl, and R. A. Zahawi. 2016. Tropical forest restoration enriches vascular epiphyte recovery. Applied Vegetation Science 19:508-517.
Robinson, G. R., and S. N. Handel. 1993. Forest restoration on a closed landfill: rapid addition of new species by bird dispersal. Conservation Biology 7:271-278.

Ruiz-Jaen, M. C., and M. T. Aide. 2005. Restoration success: how is it being measured? Restoration Ecology 13: 569-577.

Schulze, M. 2008. Technical and financial analysis of enrichment planting in logging gaps as a potential component of forest management in the eastern Amazon. Forest Ecology and Management 255:866-879.

Shono, K., S. J. Davies, and C. Y. Kheng. 2006. Regeneration of native plant species in restored forests on degraded lands in Singapore. Forest Ecology and Management 237: 574-582.

Shoo, L. P., K. Freebody, J. Kanowski, and C. P. Catterall. 2015. Slow recovery of tropical old-field rainforest regrowth and the value and limitations of active restoration. Conservation Biology 30:121-132.

Smale, M. C., and R. O. Gardner. 1999. Survival of Mount Eden Bush, an urban forest remnant in Auckland, New Zealand. Pacific Conservation Biology 5:83-93.

Smale, M. C., P. T. Whaley, and P. N. Smale. 2001. Ecological restoration of native forest at Aratiatia, North Island, New Zealand. Restoration Ecology 9:28-37.

Sporn, S. G., M. M. Bos, M. Kessler, and S. R. Gradstein. 2010. Vertical distribution of epiphytic bryophytes in an Indonesian rainforest. Biodiversity and Conservation 19:745-760.

Standish, R. J., A. W. Robertson, and P. A. Williams. 2001. The impact of an invasive weed Tradescantia fluminensis on native forest regeneration. Journal of Applied Ecology 38: $1253-1263$.

Standish, R. J., R. J. Hobbs, and J. R. Miller. 2013. Improving city life: options for ecological restoration in urban landscapes and how these might influence interactions between people and nature. Landscape Ecology 28:1213-1221.

Stinson, K. A., S. A. Campbell, J. R. Powell, B. E. Wolfe, R. M. Callaway, G. C. Thelen, S. G. Hallett, D. Prati, and J. N. Klironomos. 2006. Invasive plant suppresses the growth of native tree seedlings by disrupting belowground mutualisms. PLoS Biology 4. https://doi.org/10.1371/journal.pbio.0040140

Suding, K. N. 2011. Toward an era of restoration in ecology: successes, failures, and opportunities ahead. Annual Review of Ecology, Evolution, and Systematics 42:465-487.

Suding, K. N., and K. L. Gross. 2006. The dynamic nature of ecological systems: multiple states and restoration trajectories. Pages 190-209 in D. A. Falk, M. Palmer, and J. Zedler, editors. Foundations of restoration ecology. Island Press, Washington, D.C., USA.

Suding, K. N., and R. J. Hobbs. 2009. Threshold models in restoration and conservation: a developing framework. Trends in Ecology and Evolution 24:271-279.

Suding, K. N., K. L. Gross, and G. R. Houseman. 2004. Alternative states and positive feedbacks in restoration ecology. Trends in Ecology and Evolution 19:46-53.

Suganuma, M. S., and G. Durigan. 2015. Indicators of restoration success in riparian tropical forests using multiple reference ecosystems. Restoration Ecology 23:238-251.

Taylor, A., and K. Burns. 2015. Epiphyte community development throughout tree ontogeny: an island ontogeny framework. Journal of Vegetation Science 26:902-910.

Temperton, V. M., R. J. Hobbs, T. N. Nuttle, M. Fattorini, and S. Halle. 2004. Introduction: why assembly rules are important to the field of restoration ecology. Pages 1-8 in V. M. Temperton, R. J. Hobbs, T. N. Nuttle, and S. Halle, editors. Assembly rules and restoration ecology: bridging the gap between theory and practice. Island Press, Washington, D.C., USA. 
Threlfall, C. G., N. S. G. Williams, A. K. Hahs, and S. J. Livesley. 2016. Approaches to urban vegetation management and the impacts on urban bird and bat assemblages. Landscape and Urban Planning 153:28-39.

Tilman, D. 1985. The resource-ratio hypothesis of plant succession. American Naturalist 125:827-852.

Tyrrell, L. E., and T. R. Crow. 1994. Structural characteristics of old-growth Hemlock-hardwood forests in relation to age. Ecology 75:370-386.

Vázquez-Yanes, C., and A. Orozco-Segovia. 1982. Seed germination of a tropical rain forest pioneer tree (Heliocarpus donnell-smithii) in response to diurnal fluctuation of temperature. Physiologia Plantarum 56:295-298.

Walker, B. 1995. Conserving biological diversity through ecosystem resilience. Conservation Biology 9:747-752.

Walker, L. R., J. Walker, and R. del Moral. 2007. Forging a new alliance between succession and restoration. Pages 1-18 in L. R. Walker, J. Walker, and R. J. Hobbs, editors. Linking restoration and ecological succession. Springer, New York, New York, USA.

Walker, L. R., D. A. Wardle, R. D. Bardgett, and B. D. Clarkson. 2010. The use of chronosequences in studies of ecological succession and soil development. Journal of Ecology 98:725-736.

Wells, K., and R. B. O'Hara. 2013. Species interactions: estimating per-individual interaction strength and covariates before simplifying data into per-species ecological networks. Methods in Ecology and Evolution 4:1-8.

Winkler, M., K. Hülber, and P. Hietz. 2005. Effect of canopy position on germination and seedling survival of epiphytic bromeliads in a Mexican humid Montane forest. Annals of Botany 95:1039-1047.

Wortley, L., J. Hero, and M. Howes. 2013. Evaluating ecological restoration success: a review of the literature. Restoration Ecology 21:537-543.

Yelenik, S. G. 2016. Linking dominant Hawaiian tree species to understory development in recovering pastures via impacts on soils and litter. Restoration Ecology 25:42-52.

Zedler, J. B., and J. C. Callaway. 1999. Tracking wetland restoration: Do mitigation sites follow desired trajectories? Restoration Ecology 7:69-73.

Zotz, G., and M. Y. Bader. 2009. Epiphytic plants in a changing world-global: change effects on vascular and non-vascular epiphytes. Progress in Botany 70:147-170.

\section{SUPPORTING INFORMATION}

Additional supporting information may be found in the online version of this article at http://onlinelibrary.wiley.com/ doi/10.1002/eap.1520/full

\section{Data Availability}

Data associated with this paper are available in figshare: https://figshare.com/s/c2835178da51936fe030 